\title{
Research on the influence of boulder powder content on concrete performance
}

\author{
Guangcheng Meng ${ }^{1, *}$ \\ ${ }^{1}$ China Road and Bridge Co., Beijing 100011, China
}

\begin{abstract}
To solve the problem of environmental pollution caused by the accumulation of granite powder and the shortage of traditional mineral admixtures, the influence of the amount of granite powder on the mechanical properties of concrete was studied by replacing cement with different amount of granite powder Different amount of granite powder can be used to prepare concrete with satisfactory performance. When the amount of granite powder is small (not more than 5\%), granite powder will not reduce the compressive strength of concrete, or even slightly improve the compressive strength of pure cement concrete. When the amount of granite powder is more than 5\%, the compressive strength of concrete will gradually decrease; when the amount of granite powder is more than $5 \%$, the compressive strength of concrete will gradually decrease. The elastic modulus of concrete decreased, and the electric flux increased with the increase of the amount of admixture.
\end{abstract}

\section{Introduction}

With the increase in the scale of national infrastructure construction and the advancement of the "One Belt One Road" initiative, concrete raw materials, especially mineral admixtures, are in short supply in many regions. Fraud and adulteration of mineral admixtures (granulated blast furnace slag powder, fly ash, silicon ash, etc.) often occur, which greatly affects the quality of engineering construction. At present, many scholars are devoted to the research of new supplementary cementitious materials, such as limestone powder [1-3], metakaolin $[4,5]$ and steel slag powder [6,7], to cope with current shortage of traditional mineral admixtures.

Phnom Penh-Sihanoukville Expressway (PPSE) is an important golden channel connecting Phnom Penh, the capital of Cambodia, to Sihanouk, the largest seaport in China and an external port. The construction of PPSE is of great significance for promoting the local economic development of Cambodia and implementing the "One Belt One Road" initiative. The starting point of PPSE is at the intersection of National Highway No. 4 and Phnom Penh City Circle Line in Cambodia, and the end point is on the No. 4 road on the edge of Sihanoukville. It is about $8.6 \mathrm{~km}$ away from Sihanoukville Port to the west and about $5.5 \mathrm{~km}$ away from Westport Economy, and it is about $8.5 \mathrm{~km}$ from Sihanoukville Airport. The total length is $187.05 \mathrm{Km}$. The whole line adopts Chinese highway construction standards and specifications. The design speed is $100 \mathrm{Km} / \mathrm{h}$, and the two-way four-lane.

Table 1 Chemical composition of cement and boulders powder (BP) (wt.\%)

\begin{tabular}{|c|c|c|c|c|c|c|c|c|c|}
\hline Material type & $\mathrm{CaO}$ & $\mathrm{Al}_{2} \mathrm{O}_{3}$ & $\mathrm{SiO}_{2}$ & $\mathrm{SO}_{3}$ & $\mathrm{Fe}_{2} \mathrm{O}_{3}$ & $\mathrm{~K}_{2} \mathrm{O}$ & $\mathrm{Na}_{2} \mathrm{O}$ & $\mathrm{MgO}$ & LOI \\
\hline cement & 72.27 & 3.98 & 18.77 & 3.73 & 0.21 & 0.43 & 0.06 & 0.21 & 0.82 \\
\hline Boulder powder (BP) & 8.99 & 15.32 & 49.19 & - & 9.18 & 0.21 & 0.43 & 9.31 & 1.28 \\
\hline
\end{tabular}

\footnotetext{
* Corresponding author: menggc@crbc.com
} 
(2) Admixture: polycarboxylate superplasticizer (PS) with solid content of $16.2 \%$ and water reducing rate of $18.2 \%$ is selected.

(3) Boulder powder: the fluidity ratio of boulders powder (BP) from the preparation process of manufactured sand is $81 \%$, and the $28 \mathrm{~d}$ activity index is $60 \%$.

(4) Fine aggregate: manufactured sand made by boulders is used, which has a fineness modulus of 2.9, a stone powder content of $9.6 \%$, a methylene blue value of 1.1 .

(5) Coarse aggregate: $5-20 \mathrm{~mm}$ continuous graded crushed stone is used, and the apparent density of it is $2642 \mathrm{~kg} / \mathrm{m}^{3}$, the bulk density is $1626 \mathrm{~kg} / \mathrm{m}^{3}$, the water absorption is $1.3 \%$ and the crushing value is $6.3 \%$.

\subsection{Testing method}

The slump and expansion of concrete were tested according to the Chinese standard Standard for test method of performance on ordinary fresh concrete: $G B / T$ 50080-2016. According to the standard for the
Chinese standard Standard for test method of concrete physical and mechanical properties: GB/T 50081-2019, the compressive strength of concrete is measured. The size of the test piece is $150 \mathrm{~mm} \times 150 \mathrm{~mm} \times 150 \mathrm{~mm}$. The raw materials of concrete were mixed in the mixer for 90 s, and the test block was formed by vibration and placed in the room with temperature of $20^{\circ} \mathrm{C}$ and humidity of $90 \%$ for $24 \mathrm{~h}$. Then the mold was disassembled, and the concrete sample was transferred into the standard curing room until the testing age. According to the Chinese standard Standard for test methods of long-term performance and durability of ordinary concrete: GB/T 50082-2009, the electric flux of concrete was measured.

\subsection{Mix proportion}

The mix proportion of concrete contained BP was listed in Table 2. The content of BP accounted for $0 \%, 5 \%$, $10 \%, 15 \%$ and $20 \%$ of cementitious materials, and the concrete slump is controlled within $180 \mathrm{~mm}$ to $210 \mathrm{~mm}$ by adjusting the dosage of PS.

Table 2. Mix proportion of concrete $\left(\mathrm{kg} / \mathrm{m}^{3}\right)$

\begin{tabular}{|c|c|c|c|c|c|c|c|}
\hline Sample ID & $\begin{array}{c}\text { Water-to- } \\
\text { binder ratio }\end{array}$ & Water & Cement & $\begin{array}{c}\text { Boulder } \\
\text { powder (BP) }\end{array}$ & $\begin{array}{c}\text { Content of } \\
\text { BP(\%) }\end{array}$ & Fine aggregate & $\begin{array}{c}\text { Coarse } \\
\text { aggregate }\end{array}$ \\
\hline J-0 & 0.45 & 175.5 & 390.0 & - & 0 & 825 & 1015 \\
\hline J-5 & 0.45 & 175.5 & 370.5 & 19.5 & 5 & 825 & 1015 \\
\hline J-10 & 0.45 & 175.5 & 351.0 & 39.0 & 10 & 825 & 1015 \\
\hline J-15 & 0.45 & 175.5 & 331.5 & 58.5 & 15 & 825 & 1015 \\
\hline J-20 & 0.45 & 175.5 & 312.0 & 78.0 & 20 & 825 & 1015 \\
\hline J-25 & 0.45 & 175.5 & 292.5 & 97.5 & 25 & 825 & 1015 \\
\hline
\end{tabular}

\section{Result and discussion}

\subsection{Workability}

The influence of BP content on the workability of concrete was shown in Fig. 1, and amount of PS with different content of BP was listed in Fig. 2. It could be found that the slumps of $\mathrm{J}-0$ to $\mathrm{J}-25$ were between $180 \mathrm{~mm}$ to $210 \mathrm{~mm}$, and the largest one was the $\mathrm{J}-10$ sample with a BP content of $10 \%$ and the smallest one was the J-25 with a slump of $180 \mathrm{~mm}$. The slump and slump-flow of concrete first increased and then decreased with the increase of the BP content.

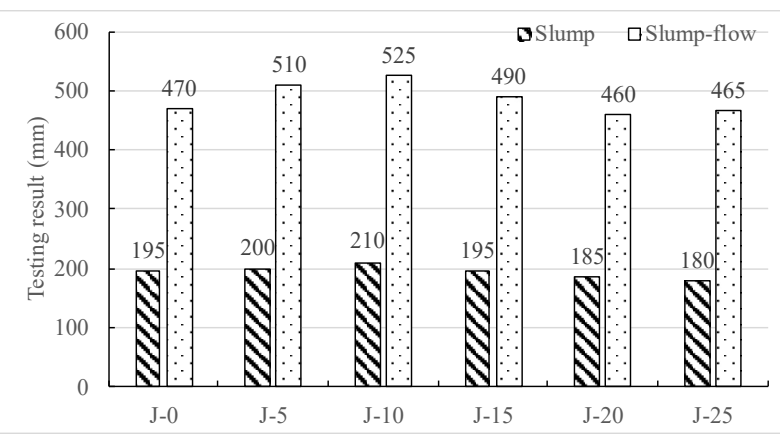

Fig. 1. Workability of concrete with different content of boulders powder.
Fig. 2 showed that the amount of PS is between $0.90 \%$ to $1.20 \%$ (the mass ratio of cementitious materials). The smallest dosage of PS was J-5 as well as $\mathrm{J}-10$, and the largest one belonged to $\mathrm{J}-25$, meaning that the usage of PS first decreased and then gradually increased with the increase of the BP content. The main reason was that the $\mathrm{BP}$ mixed into concrete contained some particle with a small particle size, which could fill the pores between cement particles and play a certain water-reducing effect. Secondly, the surface of the BP particle was relatively rough and sometimes contained a certain amount of mud powder. Under normal circumstances, the water demand was very large, and the PS would be adsorbed at the same time, which has a certain negative effect on the workability of the concrete. When the amount of BP was low, its water-reducing effect was more obvious, and the requirement of PS was reduced, while the flowability of fresh concrete was better. If the amount of BP was large, it water demand and the negative effect of adsorbing PS were prominent, and therefore the usage of PS increased and the slump as well as slump-flow of concrete became worse. 


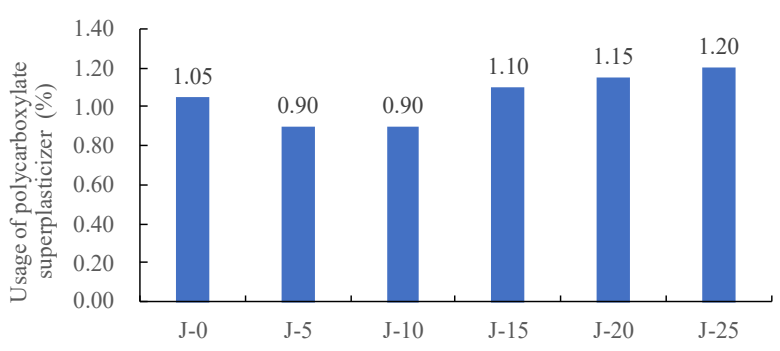

Fig. 2. Amount of polycarboxylate superplasticizer of concrete

\subsection{Compressive strength}

The influence of the amount of BP on the compressive strength of concrete was shown in Fig. 3. Taking J-0 as the controlled group, when the BP content was $5 \%$, the strength of each curing age is slightly higher than that of the controlled group. As the BP content further increased, the compressive strength continued to decrease. In order to quantify the impact of BP on the strength of concrete, this section defined the ratio of the compressive strength of the testing group mixed with BP to the strength of the controlled group as the compressive strength $\rho$, as shown in equation (1). Based on the testing result in Fig. 3, $\rho$ of different testing groups were calculated and the results were shown in Fig. 4.

$$
\rho_{i}=\left(1-f_{t, i} / f_{c, i}\right) \times 100
$$

Where $\rho_{i}$ was the compressive strength ratio of concrete in the curing age $i$ ( $\mathrm{i}=3$ days, 7days, 28 days or 56 days), $f_{t, i}$ was the compressive strength of the testing groups in the curing age $i, f_{c, i}$ was the compressive strength of the controlled strength in the curing age $i$.

The $\rho$ of J-5 at different ages were all less than 0 , indicating that the strength of J-5 was higher than that of $\mathrm{J}-0$. As the amount of BP increased, the $\rho$ value of concrete was positive and gradually increased, which meat that the compressive strength of concrete decreased more. When the amount of BP was $25 \%$, the $\rho$ of concrete at various ages were sequentially $29.8 \%, 18.8 \%$, $18.2 \%$ and $12.3 \%$. On the other hand, for concrete with the same content of BP, the addition of BP had a greater impact on the compressive strength of concrete at an early age (for example, 3 days). As the curing age increased, the adverse effect of adding BP on the strength of concrete gradually weakened.

Fig. 1 and Fig. 2 showed that when the content of BP is low (for example, $5 \%$ ), the BP particles could fill in the voids of the concrete paste, so that the particle size distribution of concrete was more reasonable, and thus the fluidity was better. The compressive strength of J-5 was also enhanced and finally slightly higher than that of J-0. When the content of BP was further increased, the workability of fresh concrete became worse, and the air bubbles were difficult to smoothly discharged during the vibration forming process of the concrete, resulting in more initial micro-defects after the concrete was hardened. In the low hydration stage, the compressive strength of concrete was weakened to a higher degree. Secondly, BP is an inert material. After replacing part of the cement, the cement clinker content would decrease, and the amount of hydration products will be reduced at the same age. The size of the pores in the cement matrix was larger, the compactness was poor, and there were many voids and cracks distributed in the interface transition zone, leading to the destruction of concrete sample under lower load.

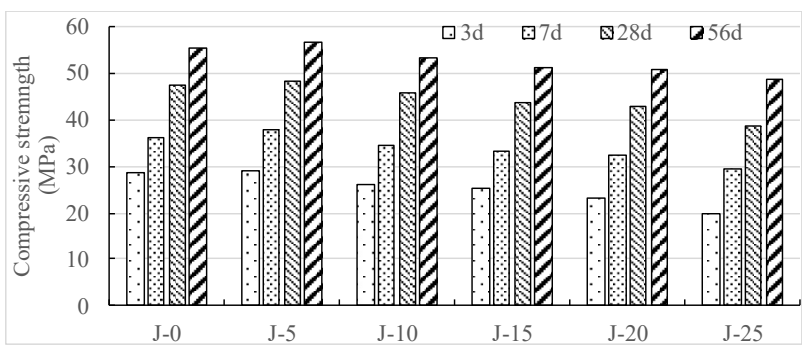

Fig. 3. Influence of boulders powder content on compressive strength of concrete

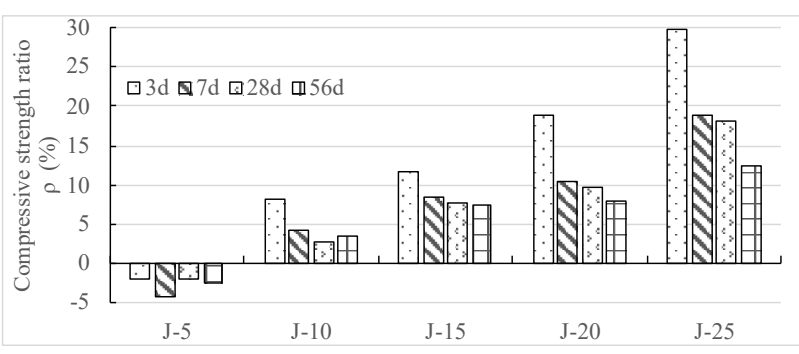

Fig. 4. Influence of boulders powder content on compressive strength ratio $\rho$ of concrete

\subsection{Elastic modulus}

Fig. 5 showed the testing results of elastic modulus of concrete mixed with different content of BP at different curing age. The elastic modulus of concrete is the ratio of compressive stress and strain, which could measure the degree of deformation and is an important parameter for the design of concrete structures. When concrete has a high elastic modulus, the structures is more resistant to deformation. Similar to the compressive strength, when the BP content was low (5\%), the elastic modulus of concrete at different ages was high than that of the controlled group, but as the BP content was increased, the concrete elastic modulus continued to decrease and the curing age prolonged could improve the elastic modulus of concrete to a lower extent.

The testing operation of elastic modulus of concrete is complicated and consume a long time, which brings inconvenience to engineering practice. Many researchers [8-11] had carried out series experiments to establish mathematical models of the relationship between the elastic modulus and compressive strength of concrete, including power function and polynomial function models, and try to use compressive strength to predict the elastic modulus of concrete. In this paper, a power function equation was used to establish a compressive strength-elastic modulus model, as shown in equation (2).

$$
E_{c}=12.715 x^{0.2854}
$$

Where $E_{c}$ was the calculated value of the elastic modulus of concrete containing $\mathrm{BP}$, and $f_{c}$ was the 
compressive strength of the concrete at the corresponding age.

Fig. 6 indicated that there was a strong correlation between the compressive strength and elastic modulus of concrete mixed with BP. After calculation, it was found that the difference between the predicted elastic modulus and the testing value in Fig. 5 was not higher than 5\%, meaning that the mathematical model could accurately predict the elastic modulus of BP concrete.

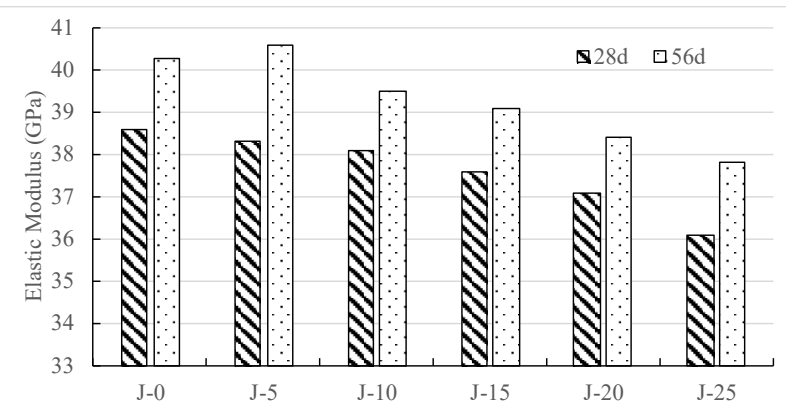

Fig. 5 Influence of boulders powder content on elastic modulus of concrete

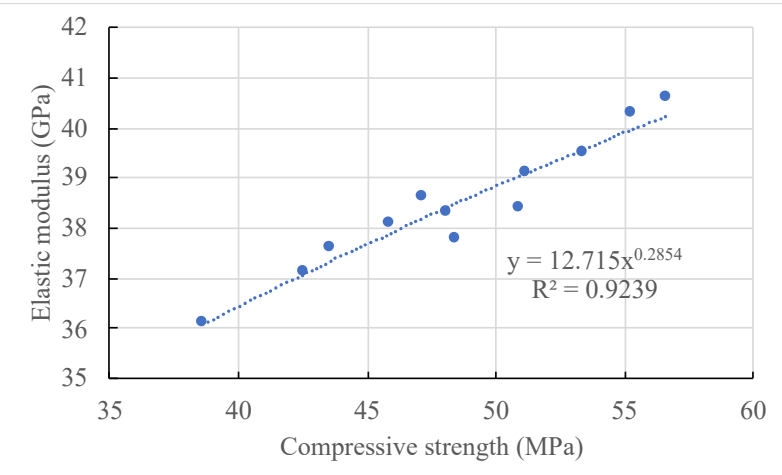

Fig. 6 The correlation of compressive strength and elastic modulus of concrete

\subsection{Electric flux}

The experimental results of the influence of BP on the electric flux of concrete were shown in Fig. 7. When the BP content did not exceed $10 \%$, increasing the BP content was beneficial to reduce the electric flux of concrete, since the BP particle could improve the particle size distribution of the concrete sample through the filling effect and could also act as nucleation sites to promote the hydration process and improve the compactness of the concrete. If the content of BP was further increased, its inert effect would reduce the amount of hydration products, and the pores of the concrete matrix could not be effectively refined during the hydration process, so that the average size of the pores was too large and the total porosity was higher. Thus, the permeability of concrete increased, and the final results of electric flux increased accordingly.

On the other hand, prolonging the curing age could effectively reduce the electric flux of concrete and compensate for the negative effect caused by the excessively high content of BP. Fig. 7 showed that when the curing age was 28 days, the electric flux of all concrete was higher than $2000 \mathrm{C}$, which was a medium permeability level[12]. When the curing age was extended to 56 days, the electric flux of all groups were between $1000 \mathrm{C}$ and $2000 \mathrm{C}$, which was decreased to the low permeability level. Among them, the electric flux of J-10 was only $1106 \mathrm{C}$, which was close to ultra-low permeability. In order to ensure that the performance of the concrete was not significantly reduced, combined with the testing results of workability, compressive strength and elastic modulus as well as electric flux of the concrete, the mixing content of BP should not exceed $10 \%$.

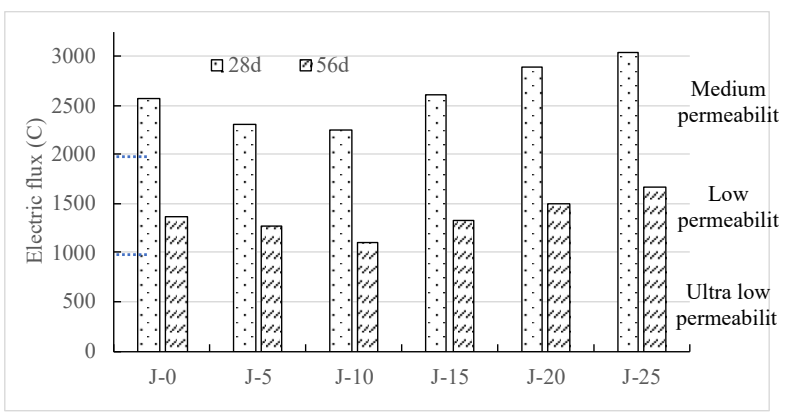

Fig. 7 Influence of boulders powder content on electric flux of concrete

\section{Conclusions}

To solve the problem of environmental pollution caused by the accumulation of boulder powder and the shortage of traditional mineral admixtures, the influence of boulder powder content on the mechanical properties of concrete was studied by replacing cement with different content of boulder powder, and the following conclusions were obtained:

(1) Different content of boulder powder could be used to prepare concrete with satisfactory workability. The usage of polycarboxylate superplasticizer could be reduced when the content of boulder powder was small (less than 10\%), and increased as the content of boulder powder increased.

(2) When the content of boulder powder was low (not more than $5 \%$ ), boulder powder would not reduce the compressive strength of concrete, and even slightly enhanced the strength at different curing age. If the content of boulder powder exceeded 5\%, the compressive strength gradually decreased with the increase of content of boulder powder.

(3) With the increase of the content of boulder powder the elastic modulus of concrete showed a downward trend, and the electric flux first decreased and then gradually increased. Prolonging the curing age could effectively compensate for the negative effects caused by the excessively high content of boulder powder. In order to ensure that the performance of concrete was not significantly weakened, the content of boulder powder should be controlled within $10 \%$. 


\section{References}

1. L. Hu and Z. He, Constr. Build. Mater. 262, 119847 (2020).

2. J. Yu, H.-L. Wu, D. K. Mishra, G. Li, and C. K. Leung, J. Clean. Prod. 278, 123616 (2021).

3. H. Du and S. D. Pang, Constr. Build. Mater. 264, 120152 (2020).

4. K. Scrivener, F. Martirena, S. Bishnoi, and S. Maity, Cement. Concrete. Res. 114, 49 (2018).

5. F. Avet and K. Scrivener, Cement. Concrete. Res. 136, 106124 (2020).

6. D. Wang, Q. Wang, and Z. Huang, Composites Part B: Engineering 198, 108207 (2020).

7. S. Zhuang and Q. Wang, Cement. Concrete. Res. 140, 106283 (2021).

8. A. F. Hashmi, M. Shariq, and A. Baqi, Constr. Build. Mater. 283, 122772 (2021).

9. C. Zhou, Z. Zhu, A. Zhu, L. Zhou, Y. Fan, and L. Lang, Constr. Build. Mater. 228, 116809 (2019).

10. Y. F. Wu, S. M. S. Kazmi, M. J. Munir, Y. Zhou, and F. Xing, J. Clean. Prod. 264, 121746 (2020).

11. J. Álvarez-Pérez, J. H. Chávez-Gómez, B. T. TeránTorres, M. Mesa-Lavista, and R. BalandranoVázquez, Constr. Build. Mater. 241, 118002 (2020).

12. R. Yang, R. Yu, Z. Shui, X. Gao, X. Xiao, D. Fan, Z. Chen, J. Cai, X. Li, and Y. He, J. Clean. Prod. 258, 120673 (2020). 